\section{Lung cancer tissue diagnosis in poor lung function: addressing the ongoing percutaneous lung biopsy $\mathrm{FEV}_{1}$ paradox using Heimlich valve}

Many centres continue to decline percutaneous lung biopsy (PLB) in patients with poor lung function (particularly FEV $1<1 \mathrm{~L}$ ) due to the theoretically increased risk of pneumothorax. This practice limits access to novel lung cancer therapies and minimally invasive surgical techniques. Our retrospective single-centre analysis of 212 patients undergoing PLB, all performed prospectively and blinded to lung function, demonstrates that using ambulatory Heimlich valve chest drain (HVCD) to treat significant postbiopsy pneumothorax facilitates safe, diagnostic, early discharge lung biopsy irrespective of lung function with neither $\mathrm{FEV}_{1}$ $<1 \mathrm{~L}$ nor transfer coefficient for carbon monoxide (TLCO) $<40 \%$ predicted shown to be independent predictors of HVCD insertion or pneumothorax outcomes. Incorporating ambulatory HVCD into standard PLB practice thereby elegantly bridges the gap that currently exists between tissue diagnosis in patients with poor lung function and the advanced therapeutic options available for this cohort.

\section{INTRODUCTION}

Image-guided percutaneous lung biopsy (PLB) is pivotal in lung cancer diagnosis with histology both determining prognosis and guiding treatment.

Pulmonary function tests (PFTs), particularly $\mathrm{FEV}_{1}$, are commonly used to risky stratify patients before PLB: BTS guidelines state that prebiopsy PFTs should be measured in all patients, with PLB contraindicated in $\mathrm{FEV}_{1}<35 \%$ predicted without further multidisciplinary team assessment. ${ }^{1}$ Additionally, it is recognised that 'most practising physicians and radiologists use a cut-off of 1 litre'. ${ }^{1}$ Similarly, BTS guidelines for surgical resection of lung malignancy deem high risk, a transfer coefficient for carbon monoxide (TLCO) $<40 \%$ predicted. $^{2}$

Notably, there is no clear literature consensus regarding the true impact of lung function on the incidence of postbiopsy pneumothorax $^{3} 4$ with little high-quality evidence in PLB practice upon which lower limits of $\mathrm{FEV}_{1}$ and TLCO are based. Accordingly, UK and North American practice is variable. ${ }^{56}$

Therapeutic options in lung cancer have advanced over the last decade, enabling treatment in patients previously precluded due to poor lung function, ${ }^{7}$ including minimally invasive surgical techniques, novel targeted drug therapies and lung sparing stereotactic radiotherapy. Despite these significant developments, UK lung biopsy practice has failed to evolve accordingly such that some patients with poor lung function continue to be declined lung biopsy, principally due to their theoretical higher risk of developing significant pneumothorax. This paradoxical practice is at direct odds with therapeutic advances tailored precisely for this particular patient subset, meaning that those potentially suitable for newer treatments are often deemed unsuitable for PLB.

In our institution, poor lung function is not a contraindication to PLB and therefore is not used as a risk-stratifying criterion, following established precedent from centres in Canada and China. ${ }^{4}{ }^{8}$ In this study, we examine the role of prebiopsy lung function tests on the safety and efficacy of PLB, facilitated by the use of ambulatory Heimlich valve chest drains (HVCDs) to manage significant iatrogenic pneumothoraces.

\section{METHODS}

Our HVCD-facilitated, early discharge lung biopsy pathway, innovative in the National Health Service (NHS) setting, has been described in a previous publication: ${ }^{9}$ we performed a retrospective blinded lung function analysis of these 489 prospectively conducted, ambulatory outpatient PLBs at the end of the study period.

All patients underwent coaxial technique PLB using: $10 \mathrm{~mL}$ 1\% lignocaine; 19G coaxial introducer needle (Argon Medical, Texas, USA); 20G core biopsy needle (Pro-mag, Argon Medical) connected to Pro-mag biopsy gun (Angiotech, Florida, USA).

PFT analysis demonstrated 212 patients for whom lung function data had been performed within 6 months of biopsy date with 188 patients demonstrating TLCO measurements. Patients with poor lung function (defined as $\mathrm{FEV}_{1}<1 \mathrm{~L}$ or TLCO $<40 \%$ predicted) were compared against those with normal lung function (defined as $\mathrm{FEV}_{1} \geq 1 \mathrm{~L}$ or TLCO $\geq 40 \%$ predicted) focusing on diagnostic histology, HVCD insertion and pneumothoraces, hospital admission, and 7 day periprocedure mortality.

Statistical analysis was performed using SPSS software (IBM SPSS Statistics V.20). Pearson's $\chi^{2}$ analysis was used for categorical variables and difference in means was tested using Student's t test for parametrical data and Mann-Whitney $U$ test for non-parametrical data.

\section{RESULTS}

Of the total 212 patients, there were 123 men and 89 women with a mean age $( \pm S D)$ of 70.4 years $( \pm 12.2)$ at the time of biopsy. The overall mean $\mathrm{FEV}_{1}$ was $1.841( \pm 0.77)$ with mean predicted $\mathrm{FEV}_{1}$ $76.4 \%$ ( \pm 24.3$)$, mean $\mathrm{FEV}_{1} / \mathrm{FVC}$ ratio $69.0 \%( \pm 14.0)$ and mean predicted TLCO $57.3 \% \quad( \pm 19.4)$. No referred patients were declined biopsy based on the subjective severity of emphysema on CT. The overall mean lesion size was $33.8 \mathrm{~mm}( \pm 18.0)$ with all patients undergoing three to six core biopsy samples.

All 212 biopsies provided a histological diagnosis with no biopsies aborted without successful completion at the same sitting. There were no biopsy-related mortalities within the measured 7 day period, and no patients required hospital admission post biopsy.

Table 1 Outcome measures in all patients compared to poor lung function groups

\begin{tabular}{|c|c|c|c|c|c|c|}
\hline \multirow[b]{2}{*}{ Outcomes } & \multicolumn{2}{|c|}{ All patients } & \multicolumn{2}{|c|}{ Low FEV 1} & \multicolumn{2}{|c|}{ Low TLCO } \\
\hline & \multicolumn{2}{|c|}{$n=212$} & \multicolumn{2}{|c|}{$\mathrm{n}=\mathbf{2 8}$} & \multicolumn{2}{|c|}{$\mathrm{n}=41$} \\
\hline \multicolumn{7}{|l|}{ Pneumothorax } \\
\hline Nil at $30^{\prime}$ & 155 & $73.1 \%$ & 21 & $75.0 \%$ & 24 & $58.5 \%$ \\
\hline Intrabiopsy & 2 & $0.9 \%$ & 0 & $0.0 \%$ & 1 & $2.4 \%$ \\
\hline Small or asymptomatic at $60^{\prime}$ & 29 & $13.7 \%$ & 4 & $14.3 \%$ & 10 & $24.3 \%$ \\
\hline Large or symptomatic at $60^{\prime}$ & 26 & $12.3 \%$ & 3 & $10.7 \%$ & 6 & $14.6 \%$ \\
\hline Total incidence pneumothorax & 57 & $26.8 \%$ & 7 & $25.0 \%$ & 17 & $41.5 \%$ \\
\hline \multicolumn{7}{|l|}{ Intervention } \\
\hline Discharge at $30^{\prime}$ without drain & 155 & $73.1 \%$ & 21 & $75.0 \%$ & 24 & $58.5 \%$ \\
\hline Discharge at $60^{\prime}$ without drain & 29 & $13.7 \%$ & 4 & $14.3 \%$ & 10 & $24.3 \%$ \\
\hline Heimlich valve drain inserted & 28 & $13.2 \%$ & 3 & $10.7 \%$ & 7 & $17.1 \%$ \\
\hline $24 \mathrm{~h}$ duration drain & 26 & $12.3 \%$ & 3 & $10.7 \%$ & 6 & $14.6 \%$ \\
\hline $48 \mathrm{~h}$ duration drain & 2 & $0.9 \%$ & 0 & $0.0 \%$ & 1 & $2.4 \%$ \\
\hline
\end{tabular}


Table 2 Independent predictors of outcome measures

\begin{tabular}{|c|c|c|c|}
\hline $\begin{array}{l}\text { Predictor } \\
\text { variables }\end{array}$ & OR & $\mathrm{Cl}$ & $\begin{array}{l}p \\
\text { Value }\end{array}$ \\
\hline \multicolumn{4}{|l|}{ HVCD insertion } \\
\hline $\mathrm{FEV}_{1}$ & 1.15 & 0.42 to 3.11 & 0.79 \\
\hline Predicted FEV 1 & 0.98 & 0.95 to 1.01 & 0.10 \\
\hline Predicted TLCO & 1.02 & 0.99 to 1.04 & 0.29 \\
\hline Lesion size & 0.95 & 0.91 to 0.98 & 0.005 \\
\hline \multicolumn{4}{|l|}{ Pneumothorax risk } \\
\hline $\mathrm{FEV}_{1}$ & 0.83 & 0.40 to 1.72 & 0.62 \\
\hline Predicted FEV 1 & 0.99 & 0.97 to 1.01 & 0.36 \\
\hline Predicted TLCO & 0.99 & 0.97 to 1.02 & 0.61 \\
\hline Lesion size & 0.96 & 0.94 to 0.98 & 0.001 \\
\hline
\end{tabular}

As table 1 demonstrates, $13.2 \%$ of all patients required HVCD insertion for a large, symptomatic postbiopsy pneumothorax (including 2/28 intrabiopsy), all of which were managed in an ambulatory outpatient setting. Twenty-six of 28 HVCDs were removed within $24 \mathrm{~h}$, with only $2 / 28$ requiring $48 \mathrm{~h}$, and no cases of recurrent pneumothoraces.

There was no evidence from our data that HVCD insertion was associated with poor lung function parameters, with an incidence of $10.7 \%(3 / 28)$ in the low $\mathrm{FEV}_{1}$ group compared with $13.6 \%(25 / 184)$ in the normal $\mathrm{FEV}_{1}$ group $(\mathrm{p}=0.91)$, and $17.1 \%(7 / 41)$ in the low TLCO group compared with $12.9 \%(19 / 147)$ in the normal TLCO group $(\mathrm{p}=0.67)$.

There was no significant difference found in the incidence of pneumothorax in the low $\mathrm{FEV}_{1}$ group, $25.0 \%$ (7/28), compared with $27.2 \%(50 / 184)$ in the normal $\mathrm{FEV}_{1}$ group $(\mathrm{p}=0.99)$. There was however, a significantly higher incidence in the low TLCO group, 41.5\% (17/41), compared with $23.8 \%(35 / 147)$ in the normal TLCO group $(p=0.04)$ though the majority were small or asymptomatic pneumothoraces not requiring intervention.

As demonstrated in table 2, binary logistic regression confirmed that neither $\mathrm{FEV}_{1}$ nor predicted TLCO were independent predictors of either the need for intervention with HVCD, or indeed the risk of pneumothorax. In fact, only a smaller lesion size was found to be predictive of HVCD insertion or pneumothorax, correlating with a reducing risk for larger lesion size, OR of $0.95(\mathrm{p}=0.005)$ and $0.96(p=0.001)$, respectively.

\section{DISCUSSION}

Our data suggest that early discharge PLB, using ambulatory HVCD, can be performed as safely and effectively in those with low $\mathrm{FEV}_{1}(<1 \mathrm{~L})$ and/or low TLCO ( $<40 \%$ predicted) as in those with normal lung function. Moreover, HVCD provision allows rapid, effective management of any significant postbiopsy pneumothorax in an outpatient, low-morbidity fashion, irrespective of lung function.

HVCD use in our ambulatory pathway has enabled the radiologist to shift the balance towards ensuring enough diagnostic tissue is obtained (and crucially away from pneumothorax risk) by allowing more core biopsy passes to be performed at one sitting, thereby meeting oncological demands for increased tissue in this era of molecular genetic subtyping. In the event of a large, symptomatic intrabiopsy pneumothorax, our practice enables continuation of biopsy with HVCD in situ, thereby ensuring diagnostic yield while managing complications in a safe, ambulatory outpatient setting. ${ }^{9}$

Incorporating ambulatory HVCD into standard PLB practice elegantly addresses the current lung biopsy ' $\mathrm{FEV}_{1}$ paradox' by directly facilitating safe biopsy, with negligible morbidity, even in those with poor lung function, making the need for prebiopsy PFT assessment an increasingly redundant practice.

Given the inherent limitations of a non-powered, retrospective design in a single-centre study, we anticipate further validated trials to confirm that restricting access to PLB due to poor lung function would appear unnecessary and be at direct odds with the more rapid and innovative evolution of both non-surgical lung cancer therapies and minimally invasive surgical techniques.

\section{R Abdullah, ${ }^{1}$ A N Tavare, ${ }^{2}$ A Creamer, ${ }^{1}$ D Creer, ${ }^{1}$ R Vancheeswaran, ${ }^{1}$ S S Hare ${ }^{2}$}

${ }^{1}$ Department of Respiratory Medicine, Barnet General Hospital, Royal Free London NHS Foundation Trust, London, UK

${ }^{2}$ Department of Radiology, Barnet General Hospital,

Royal Free London NHS Foundation Trust, London, UK
Correspondence to Dr Samanjit S Hare, Department of Radiology, Barnet Hospital, Royal Free London NHS Foundation Trust, Wellhouse Lane, EN5 3DJ, UK; samhare@nhs.net

RA and ANT are joint first authors.

Contributors SSH led the study design and performed the biopsies. RA and ANT wrote the manuscript. RA and $A C$ collected and analysed the data. DC and RV were the clinicians responsible for patient referral and helped write the manuscript.

\section{Competing interests None declared.}

Provenance and peer review Not commissioned; externally peer reviewed.

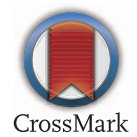

To cite Abdullah R, Tavare AN, Creamer A, et al. Thorax 2016;71:757-758.

Received 23 January 2016

Revised 5 February 2016

Accepted 21 February 2016

Published Online First 15 March 2016

Thorax 2016;71:757-758.

doi:10.1136/thoraxjnl-2016-208381

\section{REFERENCES}

1 Manhire A, Charig M, Clelland C, et al. Guidelines for radiologically guided lung biopsy. Thorax 2003; 58:920-36

2 British Thoracic Society; Society of Cardiothoracic Surgeons of Great Britain and Ireland Working Party. BTS guidelines: Guidelines on the selection of patients with lung cancer for surgery. Thorax 2001;56:89-108.

3 García-Río F, Pino JM, Casadevall J, et al. Use of spirometry to predict risk of pneumothorax in CT-guided needle biopsy of the lung. J Comput Assist Tomogr 1996;20:20-3

4 Yeow KM, Su IH, Pan KT, et al. Risk factors of pneumothorax and bleeding: multivariate analysis of 660 CT-guided coaxial cutting needle lung biopsies. Chest 2004;126:748-54.

5 Aviram G, Schwartz DS, Meirsdorf S, et al. Transthoracic needle biopsy of lung masses: a survey of techniques. Clin Radiol 2005;60:370-4.

6 Richardson CM, Pointon KS, Manhire AR, et al. Percutaneous lung biopsies: a survey of UK practice based on 5444 biopsies. Br J Radiol 2002;75:731-5.

7 Das M, Abdelmaksoud MHK, Loo BW, et al. Alternatives to surgery for early stage non-small cell lung cancer-ready for prime time? Curr Treat Options Oncol 2010;11:24-35

8 Dennie CJ, Matzinger FR, Marriner JR, et al. Transthoracic needle biopsy of the lung: results of early discharge in 506 outpatients. Radiology 2001;219:247-51.

9 Tavare AN, Creer DD, Khan S, et al. Ambulatory percutaneous lung biopsy with early discharge and Heimlich valve management of iatrogenic pneumothorax: more for less. Thorax 2016;71:190-2. 